\title{
Developing an APP with Taiwanese Image for Reminiscence Therapy of Dementia
}

\author{
Pei-Fen $\mathrm{Wu}^{1 *}$, Hui-Jiun $\mathrm{Hu}^{2}$, Kuang-Yi Fan ${ }^{3}$ \\ ${ }^{1}$ Department of Information Management \& Master program in Digital Content Technology and \\ Management, National Chunghua University of Education. 2, Shi-Da Road, Changhua City 500, Taiwan. \\ (R.O.C.) \\ ${ }^{2}$ Department of Visual Arts, National Chiayi University. 85, Wenlong, Minhsiung, Chiayi County 621, Taiwan \\ (R.O.C.) \\ 3 The Graduate Institute of Animation and Multimedia Design, National University of Tainan. 33, Sec. 2, \\ Shu-Lin St., Tainan 700, Taiwan. (R.O.C.)
}

* Pei-Fen Wu. Tel.: +886-7232105\#7517; email: pfwu@cc.cnue.edu.tw Manuscript submitted May 15, 2018; accepted June 25, 2018.

doi: $10.17706 /$ jsw.13.7.395-406

\begin{abstract}
With the changing population structure, aging of the population becomes a prominent topic that each country attaches great importance to. Many studies have been devoted to delaying the progression of dementia in the elderly, and reminiscence therapy as one of the main non-drug therapies can effectively slow down the deterioration of dementia patients. Most dementia patients remember the past and enjoy talking about their memories. This kind of life review is also a self-help method of repairing progressive brain unresponsiveness. Narration and re-storying is one of the ways to help dementia patients stimulate and restore their memories. Therefore, this study includes observing the reminiscence therapy behavior of dementia patients and caregivers in a day care center at hospital, analyses the existing storytelling system, 185 questionnaires surveyed about old Taiwan are conducted in eight categories to match the reminiscence imagery therapy, then develops the ReStor APP, and plans and implements the design of acceptable technology experiences for dementia patients. The study expects to slow down the mental decline of patient's and fill the memory voids of the elderly and their families. The research developmental the APP that providing reference values for specific elderly user experiences in Taiwan, the images database is used will benefit in providing reference for the design of memory for Taiwan's elderly.
\end{abstract}

Key words: Dementia, digital storytelling, elderly, reminiscence therapy.

\section{Introduction}

According to the Department of Economic and Social Affairs of the United Nations World Population Prospects [1], as released in 2017: the 2012 Revision suggests that, globally, the number of persons aged 80 or over is projected to triple by 2050, from 137 million in 2017 to 425 million in 2050. By 2100 it is expected to increase to 909 million, which is nearly seven times the value of 2017. Population ageing is projected to have profound effect on societies, underscoring that the fiscal and political pressures of the health care, old-age pension, and social protection systems of many countries are likely to face in the coming decades. Moreover, cognitive ability decline caused by aging can reduce their own living ability, as a 
result, family and social support shall be increased. The onset of dementia is slow and persistent, and the early symptoms are not obvious; however, once evident, the dementia phase could be severe. Therefore, the initial introduction of ameliorating treatment will effectively improve such deterioration. Within the cognitive and memory training in the elderly, forgetfulness can be improved by cognitive function training or external memory aids [2]-[4]. Many studies are devoted to dementia issues, in addition to drug therapy, non-drug therapy can improve declining cognitive symptoms, such as cognitive and memory training, reminiscence therapy, music therapy, horticulture therapy, etc. [5], [6]. Among them, reminiscence therapy is often used for the health care activities of dementia patients, as it emphasizes that the process of memory is a pleasant experience; meaning it is an important way to maintain dementia patient's physical and mental health, as well as their quality of life. Through re-experiencing familiar activities, it allows dementia patients to create a link to past life events, which produces confidence and pleasure [7], [8]. Rubin, Rahhal \& Poon [9] pointed out that, when people look back on their lives, they produce a Reminiscence Bump. Hepper, Ritchie, Sedikides, \& Wildschut [10] also believed that reminiscence can cause more intense and positive responses.

Klein and Boals [11] observed that the process of "storytelling" involves complex cognitive processes, including imagination, organizational ability, and narrative ability, which are simultaneously applied in storytelling. Through repeating stories, dementia patients can reopen channels of communication, which can enable younger generations to learn from their life experiences, and recount the knowledge that was unable to be clearly recorded in traditional texts. Moreover, it can fill the memory gaps of the elderly. However, relevant story-telling studies mostly took children or general ethnic groups as the development subjects, or took the form of teaching scientific knowledge [12]. Sometimes, the teaching objectives are language proficiency or training narrative writing ability [13]. The current related system developments include Storybird, Photo Story, Imagistory, Puppet Pals, etc., while few take dementia patients as the main users. Based on the above research background motivation, this study develops a set of digital storytelling apps that dementia and caregivers can use together to help dementia patients stimulate their cognitive ability by recounting their life stories through reminiscence therapy, thus, promoting their self-affirmation and self-confidence, in order to achieve the goal of delaying mental decline. The research developmental the APP for specific objects, and providing reference values for specific elderly user experiences in Taiwan, the images database is used will benefit in providing reference for the design of memory for Taiwan's elderly.

\section{Lecture Review}

\subsection{Dementia}

Dementia is often one of the most misunderstood conditions in medicine today. Dementia is that significant loss of intellectual abilities, such as memory capacity, that is severe enough to interfere with social or occupational functioning. Criteria for the diagnosis of dementia include impairment of attention, orientation, memory, judgment, language, motor and spatial skills, and function. By definition, dementia is not due to major depression or schizophrenia. Alzheimer's disease is the most common cause of dementia. Dementia is often one of the most misunderstood conditions in medicine today. Dementia refers to the significant loss of intellectual abilities, such as memory capacity, which is severe enough to interfere with social or occupational functioning [14]. Dementia patients have a normal conscious state with impaired cognitive performance, and is a common mental illness associated with an increase in the incidences of aging. The higher the age, the higher the prevalence rate of dementia, and there is a doubling trend of this prevalence rate every 5 years.

Dementia is a broad term which covers many different conditions, including Alzheimer's disease, vascular dementia, frontotemporal dementia, and other disorders. Simple forgetfulness is not enough to lead to a diagnosis of dementia, as there needs to be evidence of problems in at least two areas of cognition (brain 
function) to confirm this diagnosis. The stages of dementia are used when a progressive dementia has been diagnosed. The stages include [14]:

Stage 1: No impairment. The patient has no problems.

Stage 2: Questionable impairment. The patient begins to have some difficulty but can still function independently.

Stage 3: Mild impairment. The patient has obvious, but still mild difficulty with daily activities.

Stage 4: Moderate impairment. The patient needs help with caring for him or herself as well as with carrying out daily activities. Stage 5: Severe Impairment; patients are unable to function independently.

\subsection{Reminiscence Therapy}

Woods [15] pointed out that reminiscence therapy is a non-conflict, non-invasive approach, which is achieved by the reminiscence process, meaning the elderly can recall past profound life experiences, which increases the interactions between the elderly and others; therefore, it is suitable for use with dementia patients. Sellers \& Stork [16] defined reminiscence therapy as the original, well planned, and independent care triggering a case's review of past experiences, ideas, and feelings. Kovach [17] explained that reminiscence therapy is a mental process that reviews past events that are meaningful and influential to individuals. Reminiscence therapy is suitable for use with the elderly population, as it uses past events, feelings, and ideas to guide the reminiscence of past life, helps the elderly relive fragments their past life, and gives them new interpretation. This treatment can help the elderly to understand themselves, reduce their sense of loss, increase their self-esteem, and promote socialization [18]. Soltys \& Coats [19] proposed that the reminiscence therapy model has 3 main parts: processes, items, and outcomes.

There are two main methods of reminiscence therapy: 1) group therapy with a specific structure; 2) individual therapy of no fixed structure. The group process emphasizes the need to respect individual differences, to listen, not to criticize, and to encourage members to share their knowledge, ideas, and problem-solving skills [20]. The advantages of this method is to share with each other, learn how to communicate within a group, and increase the ability to interact with the community [21]. Group reminiscence therapy can promote cohesion and communication of parent-child relationships between the elderly and the group [22].

Group reminiscence therapy: usually there are 6-10 members, if there are elderly with mental dysfunction or disorder, there should be fewer than 6. The treatment duration is approximately 6-10 weeks, with 1-2 sessions per week and 30-90 minutes per discussion [23]. The theme of the meeting is usually a topic of common concern among the members, and preferably closely related to the experiences of the past. Although dementia patients have cognitive impairment, through familiar subject-style guidance, the sessions can help dementia patients return to the deep-rooted happy memories of the past to provide psychological comfort, gain the feeling of "presence" during activities, and enhance the sense of reality among dementia elderly, thus, reducing problematic behavior and improving self-esteem.

Individual reminiscence therapy: It takes form as one-on-one interviews, which are more suitable for dementia patients who are less focused or less sociable. Treatment sessions are 6-12 times, with each session about 20-30 minutes [16]. Chao, Chen, Liu, \& Clark [24] suggested that individual reminiscence therapy processes can be divided into 4 stages. The first stage is entrée, where listening and establishing a relationship are performed to guide a review of meaningful life experiences from the past. The second is immersion; attention should be paid to the elderly people's reactions when reviewing the past, as well as their ability to deal with negative emotions. The third is withdrawal; from the memories of the past, the patients can return to their current real life and conduct comparisons, which can help the elderly to effectively transform negative emotions into positive emotions and increase their responsive ability. The fourth is closure, which is characterized by listening to the memories of the elderly and integrating their 
past experiences.

The process of reminiscence therapy emphasizes spontaneously recalling contents, which must never be persistently inquired about or forced [25]. In the process, it is suggested to use a number of stimuli that reflect past patterns of life or provide a different sensory stimulus for memories. It is suggested that nonverbal communication, such as gestures or expressions, should be added to make the older person more aware of the interaction.

\subsection{Figures Elderly Users' Action Device Interface Design Principles}

The aging phenomenon changes of the elderly, which were caused limitations by the three of physiological, psychically and cognition functions. Various literatures studied the factor influences the preference of the elderly when using new technological products. The relevant issues were discussed and analyzed focused on the three aspects of physiological, psychically and perceptual changes of the elderly caused by ageing, and which causes them to feel unfamiliar and inconvenient when using new technology products [24] [26] [27] [28]. Williams, Alam, Ahamed, \& Chu [29] explored some common problems older users face when operating technological devices, including cognition, auditory, haptic, visual, and motor-based troubles.

User Experience Design (UXD) is the mainstream contemporary users design; it provides users with friendly operation. Norman [30] defined UXD that is the extent to which a system, product or service can be used by specified users to achieve specified goals with effectiveness, efficiency and satisfaction in a specified context of use. UXD includes elements of interaction design, that is, the User-Oriented Design to make the interface more consistent with user expectations [31]. The action interface should reduce the burden on short-term memory [32]. The system operation message must be clearly visible, and the operational function should be appropriately matched to the user, in order to facilitate understanding and eliminate the gap between execution and evaluation [31]. During the initial sensory stage of the operation, the user usually obtains the information of a product in an intuitive manner, thus, designers can consider turning to the uniqueness and metaphor within the design.

User interface design is an important issue that is paid much attention in recent years. It is used to discuss the interactions between human and computers and increase the usability of the products [33]. Shneiderman \& Plaisant [32] pointed out that the interface functions and content of the layout attach great importance to uniformity and consistency; while operation and feedback actions must be flexible. As the logical thinking, attention, memory, and other aspects of senior people have slowed, the interface design should be concise and easy to use. In the operational perception and sensory stage, the user can intuitively manipulate the product with a clear mental model [34] [35]. The purpose of elder design shall have a clear-interface and be user-friendly, in order that the elderly feel it is convenient and easy-to-use, thus, enhancing their intention of using it. Action device products should consider the physical and mental adjustments of the elderly, in order that users can enjoy a healthier and happy life. Product usability is from the user's point of view, and must ensure that interactive products are easy to learn, can be effectively used, and bring a pleasant experience to the elderly people. Moreover, action device nowadays is with various functions, and how to design to obtain results suitable for elderly is the main purpose of the study.

\section{Method}

The subjects of this study are 12 mild dementia patients in day care center at Lukang Christian Hospital, and the experiment includes three weeks of behavior observations of dementia patients during reminiscence therapy activities. The author also interviews a total of three health caregivers, and conducts analysis of the existing narrative system design principles as the research basis of dementia patients' behavioral model development. APP design combines recording and images to present the story content, 
thus, making the story creation process more intuitive. The simplified operation of the interface can effectively assist the dementia patients in telling and saving their story. In the preliminary stage of this study, the existing digital storytelling application software is analyzed first.

Before the APP was built, this study collected and analyzed related digital storytelling literature, as well as the systems available on the market, and proposed the common principles of existing digital storytelling application software.

Digital storytelling is the systematic manifestation of the elements of a story in different digital media, such as images, graphics, sound and music etc. [36]. Compared with the traditional storytelling approach, the listener of digital storytelling is no longer just a listener, they can interact with the story itself, or even shape the story [37] (Psomos \& Kordaki, 2012). At present, the relevant application software with higher usage rate is Storybirds, Photo Story, Puppet Pals, and Toontastic Jr. Pirates, which are sorted and shown in Table 1.

Table 1. Digital Storytelling Software Analysis

\begin{tabular}{|c|c|c|}
\hline \multicolumn{2}{|c|}{ Storybirds (APP_Android \& iOS) } & \multirow{2}{*}{ 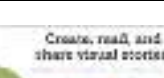 } \\
\hline Subjects & General population, Teachers and Students & \\
\hline Type & A long story, a sketch, a short poem & \\
\hline Functions & $\begin{array}{l}\text { Provide a variety of versions and optional picture creations; the area next to the picture } \\
\text { space is reserved for inputting story content. After saving the story, one can choose whether } \\
\text { to share it. }\end{array}$ & \\
\hline \multicolumn{2}{|r|}{ Photo Story (APP_Android) } & \multirow{4}{*}{$4 \frac{1}{2}=$} \\
\hline Subjects & General population & \\
\hline Type & Tell stories with help of a series of pictures & \\
\hline Functions & $\begin{array}{l}\text { Edit the static photos into a dynamic movie; the pictures can be easily edited, and add } \\
\text { background music, title, text, and narration. Music can be selected by the user or use built-in } \\
\text { sound effects. }\end{array}$ & \\
\hline \multicolumn{2}{|c|}{ Puppet Pals (APP_Android \& iOS) } & \\
\hline Subjects & Students & \\
\hline Type & Create real-time animated stories with animation and sound & \\
\hline Functions & $\begin{array}{l}\text { Provide the story stage; users may use video, recordings, and the scene switches to create } \\
\text { their story. Users can adjust the scale and rotation of objects. The saved story can be } \\
\text { viewed or exported to their own mobile devices, or uploaded to the Youtube platform for } \\
\text { sharing. }\end{array}$ & \\
\hline \multicolumn{2}{|c|}{ Puppet Pals 2 (APP_Android \& iOS) } & \\
\hline Subjects & Students and General population & \\
\hline Type & Create real-time animated stories with animation and sound & \\
\hline Functions & $\begin{array}{l}\text { During the creative process, users can select built-in vehicles, scenes, music, and } \\
\text { characters, or select DIY. In addition, the APP provides exquisite and highly flexible and } \\
\text { highly-animated character movements. }\end{array}$ & \\
\hline \multicolumn{2}{|c|}{ Toontastic Jr. Pirates ( APP_Android \& iOS ) } & \\
\hline Subjects & Students and General population & \\
\hline Type & Write animation narrative structure and thinking & \\
\hline Functions & $\begin{array}{l}\text { With a piece of animation to guide the creation of the story, the creation process is } \\
\text { equipped with a three-act story structure; and sound can be recorded and dubbed. When } \\
\text { completed, it can be shared through the platform. }\end{array}$ & \\
\hline
\end{tabular}

The above mentioned story application software presents a variety of ways to tell stories, such as the provision of sections, and a large number of pictures. The static pictures are edited into a dynamic video, and background music and voice narration recordings are added. Users can upload to the cloud platform to share with others. The common features of such digital storytelling software are mainly for the convenience of the user to create their own digital stories; they can also save it digitally, and achieve resource sharing. However, if one can design special software for dementia users that follow the existing software characteristics and allow dementia patients to memorize and record their past story, as well as their mental process, it will be of greater significance for dementia patients, their families, and the caregivers. 
A questionnaire survey was conducted in old Taiwan, matched the reminiscence imagery therapy, for the APP' images database. There were total of 185 subjects surveyed, questionnaires were conducted in categories including Taiwanese characteristics, childhood, food, costume, architecture, vehicle, and education etc.

\section{Design and Development the APP}

\subsection{Design Concept of APP}

Elderly people often cherish their memories of the past, and by sharing, they can gain their own sense of existence; however, due to the gradual decline of memory, all that remains are deep memories of the past, thus, they tend to repeat the same matter vividly, but often do not clearly remember more recent things and people. If we can help them slow down dementia, and record their past, we will be able to fill the memory voids of dementia patients.

This study named its APP "ReStor", which is a combination of re-story and restore, with the meaning of re-memorizing and memory storage, and dementia patients and caregivers can easily use it. Through the process of re-narration of past stories, memory will be strengthened to slow down the degradation brought about by dementia. It is hoped that the "ReStor" process can reopen past stories to help the elderly regain their memory and enhance their cognitive functions. With this APP, they can keep a story intact and present the story through "ReStor", and share their story with others without worrying about forgetting or repeating it.

\subsection{The Language of ReStor APP System' Development}

In the System software section, Adobe CC is used to build the system; the Android system is used for the development language, which is supplemented by the Android studio for APP. Fig. 1 is the structure diagram and flowchart of this system.

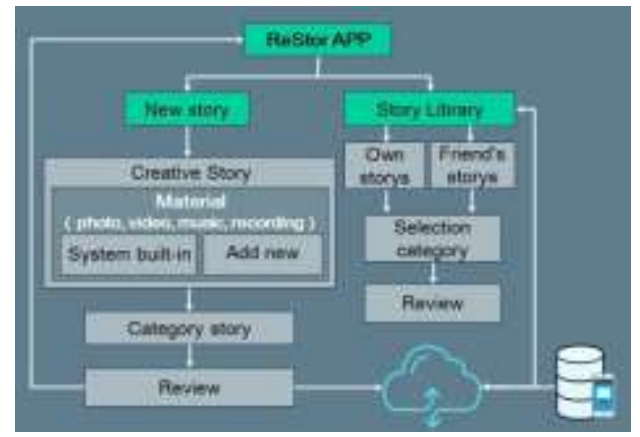

Fig. 1. The ReStor app system architecture diagram.

When the APP is finished, the first edition will be evaluated by an expert, and after being used by dementia patients, the author will correct the APP's design problems.

\subsection{ReStor APP Conception of Prophase Construction}

This APP design combines recordings and images to present story content, thus, making the story creation process more intuitionistic and reducing the difficulty of interface operation, which can effectively help the elderly with dementia to perform story creation. Design essentials include (Fig. 2 and Fig. 3):

1. Provide 2 kinds of story creation methods, one is built in the system; another is that users can add their own materials (including photos, music, movies).

2. Considering that users shall use the system in the most intuitive manner, both recordings and handwritten input methods are provided to record the story content. 
3. The files produced by ReStor APP are stored in the cloud for system recordings, file building, analysis, and sharing.
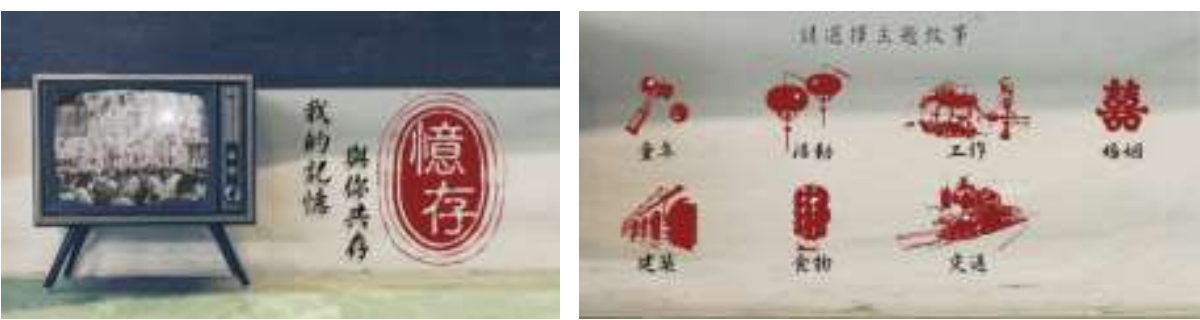

Fig. 2. The user interface of ReStor APP.

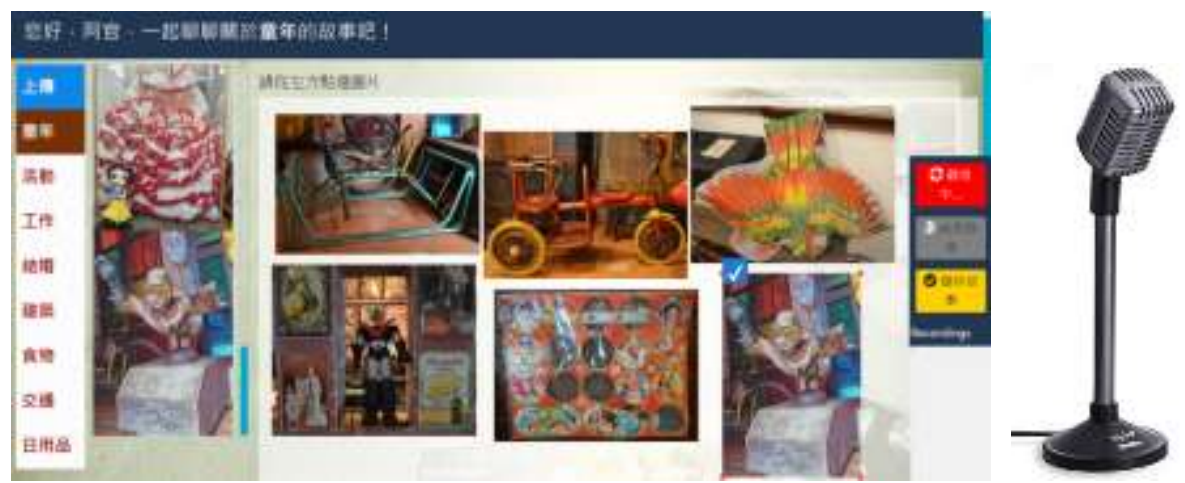

Fig. 3. The audio recording interface and equipment of ReStor APP.

\subsection{The Exploring of Taiwan's Memory}

A questionnaire survey was conducted in old Taiwan, matched the reminiscence imagery therapy, for the APP' images database. Questionnaires were conducted in categories including Taiwanese characteristics, childhood, food, costume, architecture, vehicle and education. There were total of 185 valid questionnaires. Table 2 shows the top ten representative features of Taiwan native characteristics.

Table 2. The Top Ten Representative Features of Taiwan Native Characteristics

\begin{tabular}{llll}
\hline \hline \multicolumn{2}{l}{ Taiwan native characteristics } & Total number of respondents & Percentage \\
\hline 1. & Mazu god walk around county & 128 & $69.10 \%$ \\
\hline 2. & Temple fair & 124 & $67 \%$ \\
\hline 3. & pilgrimage & 122 & $65.90 \%$ \\
\hline 4. & Puppet show & 104 & $56.20 \%$ \\
\hline 5. & Parade Formation & 102 & $55.10 \%$ \\
\hline 6. & Taiwanese opera & 98 & $52.90 \%$ \\
\hline 7. & Roadside banquet & 93 & $50.20 \%$ \\
\hline 8. & Night market & 91 & $49.10 \%$ \\
\hline 9. & Dragan Boat Festival Scorpion & 89 & $48.10 \%$ \\
\hline 10. & Snack food & 88 & $47.50 \%$ \\
\hline \hline
\end{tabular}

Table 3 shows the top five childhood memories in reminiscence imagery.

Table 3. The Top Five Childhood Memories in Reminiscence Imagery

\begin{tabular}{llcl}
\hline \hline Childhood memories & Total number of respondents & Percentage \\
\hline 1. & spin a whipping top & 138 & $74.50 \%$ \\
\hline 2. & Jumping lattice, hopscotch, jumping tire & 135 & $72.90 \%$ \\
\hline 3. & Jump rubber band & 125 & $67.50 \%$ \\
\hline 4. & Sandbags & 118 & $63.70 \%$ \\
\hline 5. & Marbles and pinballs & 117 & $63.20 \%$ \\
\hline \hline
\end{tabular}


Table 4 shows the top five evocative foods.

Table 4. The Top Five Evocative Foods

\begin{tabular}{llcl}
\hline \hline \multicolumn{2}{l}{ Evocative food } & Total number of respondents & Percentage \\
\hline 1. & Homemade mungbean ice & 119 & $64.30 \%$ \\
\hline 2. & Buboo ice cream & 118 & $63.70 \%$ \\
\hline 3. & Roasted wheat flour & 109 & $58.90 \%$ \\
\hline 4. & Taiwanese popcorn & 107 & $57.80 \%$ \\
\hline 5. & Shaved ice & 107 & $57.80 \%$ \\
\hline \hline
\end{tabular}

Table 5 shows the Top five in reminiscent costumes.

Table 5. The Top Five in Reminiscent Costumes

\begin{tabular}{llcl}
\hline \hline \multicolumn{2}{l}{ Evocative food } & Total number of respondents & Percentage \\
\hline 1. & Primary school cap & 140 & $75.60 \%$ \\
\hline 2. & braces skirt & 128 & $69.10 \%$ \\
\hline 3. & bamboo hat & 120 & $64.80 \%$ \\
\hline 4. & bell-bottomed pants & 115 & $62.10 \%$ \\
\hline 5. & uniform & 105 & $56.70 \%$ \\
\hline \hline
\end{tabular}

Table 6 shows the Top five Taiwanese architecture in reminiscent imagery.

Table 6. The Top Five Taiwanese Architecture in Reminiscent Imagery

\begin{tabular}{llcl}
\hline \hline \multicolumn{2}{l}{ Architecture } & Total number of respondents & Percentage \\
\hline 1. & Three section courtyard house & 175 & $94.50 \%$ \\
\hline 2. & grocery store & 142 & $76.70 \%$ \\
\hline 3. & Rammed-Earth House & 122 & $65.90 \%$ \\
\hline 4. & Ancient well & 119 & $64.30 \%$ \\
\hline 5. & Temple & 107 & $57.80 \%$ \\
\hline \hline
\end{tabular}

Table 7 shows the Top five vehicles reminiscent images in Taiwan.

Table 7. Top Five Vehicles Reminiscent Images in Taiwan

\begin{tabular}{llcl}
\hline \hline \multicolumn{2}{l}{ Vehicle } & Total number of respondents & Percentage \\
\hline 1. & Bicycle & 154 & $83.20 \%$ \\
\hline 2. & Vespa Motorcycle & 133 & $71.80 \%$ \\
\hline 3. & Wild wolf Motorcycle 125 & 130 & $70.20 \%$ \\
\hline 4. & Ox cart & 118 & $63.70 \%$ \\
\hline 5. & Highway bureau & 102 & $55.10 \%$ \\
\hline \hline
\end{tabular}

Table 8 shows the top five reminiscent images of Taiwan's education.

Table 8. The Top Five Reminiscent Images of Taiwan's Education

\begin{tabular}{llcl}
\hline \hline \multicolumn{2}{l}{ Education reminiscent images } & Total number of respondents & percentage \\
\hline 1. & Joint College Entrance Exam. & 145 & $78.30 \%$ \\
\hline 2. & $\begin{array}{l}\text { Ascending and descending flags } \\
\text { ceremony }\end{array}$ & 143 & $77.20 \%$ \\
\hline 3. & Ban on hairstyles & 142 & $76.70 \%$ \\
\hline 4. & Corporal punishment & 139 & $75.10 \%$ \\
\hline 5. & Civics ad virtue course & 129 & $69.70 \%$ \\
\hline \hline
\end{tabular}

Other Reminiscent Images of Taiwan are shown in Table 9. 
Table 9. Other Reminiscent Images of Taiwan

\begin{tabular}{llll}
\hline \hline Other Reminiscent Images of Taiwan & Total number of respondents & percentage \\
\hline 1. & Marriage customs & 101 & $61.20 \%$ \\
\hline 2. & Career ( bus girl, farmer, fisherman... ) & 82 & $49.60 \%$ \\
\hline 3. & $\begin{array}{l}\text { Family or children's activities (a } \\
\text { vocational inclination test for an infant, } \\
\text { coming-of-age ceremony, family party...) }\end{array}$ & 70 & $42.40 \%$ \\
\hline 4. & $\begin{array}{l}\text { Military career (the place joins the } \\
\text { army, Glory deeds) }\end{array}$ & 56 & $33.90 \%$ \\
\hline \hline
\end{tabular}

According to the analysis results of Table 2 - Table 9, the basis for the database of reminiscent images in Taiwan is established.

\section{Conclusion}

\subsection{Conclusions and Suggestions}

Dementia, which has increasing incidences, is a common type of senior mental illness. The consequences of dementia include the decline of memory, functional degradation in other cognitive functions, and various other aspects. It affects the elderly's own life, and is a heavy burden to the family and the community. Studies have found that memory and language skills can affect the health and social skills of older people. The repetitive behavior of elderly people is activated by their brain, thus, elderly who are willing to communicate with others have the opportunity to slow down their degeneration and social isolation phenomenon, meaning they can establish links with the outside world, and conduct review of themselves through narration. In today's dementia treatments, reminiscence therapy is one of the non-drug therapy methods, which trigger the memories of dementia elders by means of audio-visual images associated with past life experiences, leading dementia elders to retell and share life stories, thus, achieving the goal of self-affirmation and increasing self-confidence. The narrative of a story is one of the most important pipelines of life experience, which can be clearly recorded through the development of this digital storytelling APP.

This study includes observing the user experience of reminiscence therapy behavior of dementia patients and caregivers in a day care center at Lukang Christian Hospital. Firstly, analyses the existing storytelling system. Secondly, there are 185 questionnaires surveyed about old Taiwan are conducted in eight categories to match the reminiscence imagery in Taiwan. Then develops the ReStor APP, and plans and implements the design of acceptable technology experiences for dementia patients. This research earnestly looks forward to the development of this APP, as it will enable the elderly to repeat their stories and reopen their external channels of communication. This would enable younger generations to learn from the stories and life experiences of the elderly during their prime, and recount knowledge that was unable to be clearly recorded in traditional Chinese texts. The memory void of elderly dementia patients will be finally filled.

\subsection{Future Research}

This study is in the design and development stage; future studies will be carried out according to the usability survey of this APP, as well as observations of dementia patients' storytelling and their usage experience. Further developments will be made on the digital ReStor APP according to user demands; and through evaluation of the reminiscence therapy scale, the author will explore the effects of this digital ReStor APP on mild dementia patients for slowing down the degradation of their cognitive ability and promoting their self-confidence.

\section{References}

[1] Department of Economic and Social Affairs of the United Nations. World Population Prospects. (2017). 
Retrieved May 12, 2018 from https://www.un.org/development/desa/publications/world-populatio n-prospects-the-2017-revision.html.

[2] Beigl, M. (2000). MemoClip: A location-based remembrance appliance. Personal Technologies, 4(4), 230-233.

[3] DeVaul, R. W., \& Corey, V. R. (2003). The memory glasses: Subliminal vs. overt memory support with imperfect. IEEE International Symposium on Wearable Computers. doi: 10.1109/ISWC.2003.1241404

[4] Levinson, R. (1997). The planning and execution assistant and trainer (PEAT). Head Trauma Rehabilitation, 12, 769-775.

[5] Ball, J., \& Haight, B. (2005). Creating a multisensory environment for dementia: The goals of a Snoezelen room. J Gerontol Nurs, 31(10), 4-10.

[6] Hope, K. (1998). The effects of multisensory environments on older people with dementia. J Psychiatr Ment Health Nurs, 5, 377-386.

[7] Mcdougall, G. J., Blixen, C. E., \& Suen, L.-J. (1997). The process and outcome of life review psychotherapy with depressed homebound older adults. Nursing Research, 46(5), 277-283.

[8] Watt, L. M., \& Cappeliez, P. (2000). Integrative and instrumental reminiscence therapies for depression in older adults: Intervention strategies and treatment effectiveness. Aging and Mental Health, 4(2), 166-177.

[9] Rubin, D. C., Rahhal, T. A., \& Poon, L. W. (1998). Things learned in early adulthood are remembered best. Memory \& Cognition, 26(1), 3-19. doi: 10.3758/BF03211366.

[10] Hepper, E. G., Ritchie, T. D., Sedikides, C., \& Wildschut, T. (2012). Odyssey's end: Lay conceptions of nostalgia reflect its original homeric meaning. Emotion, 12(1), 102. doi: 10.1037/a0025167

[11] Klein, K., \& Boals, A. (2001). Expressive writing can increase working memory capacity. Journal of Experimental Psychology: General, 130, 520-533.

[12] Fridin, M. (2014). Storytelling by a kindergarten social assistive robot: A tool for constructive learning in preschool education. Computers \& Education, 70, 53-64.

[13] Yang, Y.-T. C., \& Wu, W.-C. I. (2012). Digital storytelling for enhancing student academic achievement, critical thinking, and learning motivation: A year-long experimental study. Computers \& Education, 59(2), 339-352.

[14] Taylor, D. C. (2018). Medical Definition of Dementia, Retrieved March 10, 2018, from https://www.medicinenet.com/script/main/art.asp?articlekey=2940.

[15] Woods, R. T. (1996). Handbook of the clinical psychology of aging. NY: Wiley \& Sons.

[16] Sellers, S., \& Stork, P. (1997). Reminiscence as an intervention: Rediscovering the essence of nursing. Nursing Forum, 32(1), 17-23.

[17] Kovach, C. (1991). Reminiscence: Exploring the origins, process, and consequence. Nursing Forum, 26(3), 14-20.

[18] Connie, T. (1995). The efficacy of structured reminiscence group psychotherapy as an intervention to decrease depression and increase psychological well-being in female nursing home residents. Mississippi State University, Mississippi.

[19] Soltys, F. G., \& Coats, L. (1995). The SolCos model: Facilitating reminiscence therapy. Journal of Psychosocial Nursing \& Mental Health Services, 33(11), 21-26.

[20] Soltys, F. G., Reda, S., \& Letson, M. (2002). Use of the group process for reminiscence. Journal of Geriatric Psychiatry, 35(1), 51-61.

[21] Burnside, I., \& Haight, B. (1994). Reminiscence and life review: Therapeic interventions for older people. Nurse Practitioner, 19(4), 55-61.

[22] Bender, M., Bauckham, P., \& Norris, A. (1999). The Therapeutic Purposes of Reminiscence. London: SAGE. 
[23] Ashton, D. (1993). Therapeutic use of factors influencing adjustment among relocating rural elders. Image-the Journal of Nursing Scholarship, 28(1), 35-38.

[24] Chao, S.-Y., Chen, C.-R., Liu, H.-Y., \& Clark, M. J. (2008). Meet the real elders: Reminiscence links past and present. Journal of Clinical Nursing, 17(19), 2647-2653.

[25] Haight, B., \& Burnside, I. (1993). Reminiscence and life review: Explaining the differences. Archives of Psychiatric Nursing, 7(2), 91-98.

[26] Eisma, R., Dickinson, A. Goodman, J. Syme, A. Tiwari, L., \& B Newell, A. F. (2004). Early user involvement in the development of information technology related products for older people. Universal Access in the Information Society, 3(2), 131-140.

[27] Gregor, P., \& Dickinson, A., (2005). Cognitive difficulties and access to information systems: An interaction design perspective. ACM SIGACCESS Accessibility and Computing, 83, 59-63.

[28] Zhao, C., et al., (2008). Understanding older vehicle users: an interpretative approach. Proceedings of the 2008 Design Research Society Conference, (pp.775 - 779). Sheffield Hallam University Research Archive. Retrieved May 18, 2018, from http://shura.shu.ac.uk/516/.

[29] Williams, D., Alam, M. A. U., Ahamed, S. I., \& Chu, W. (2013). Considerations in designing human-computer interfaces for elderly people. Proceedings of the 13th International Conference on Quality Software. (pp. 372-377).

[30] Norman, D. (2002). The design of everyday things. New York, NY: Basic Books.

[31] Laurel, B. (1990). The Art of Human-Computer Interface Design. MA: Addison-Wesley.

[32] Shneiderman, B., \& Plaisant, C. (2005). Designing the User Interface: Strategies for Effective Human-Computer Interaction: Pearson/Addison Wesley.

[33] Finstad, K. (2010). The Usability Metric for User Experience. Interacting with Computers, 22, 323-327.

[34] Hoober, S., \& Berkman, E. (2012). Designing Mobile Interfaces. O’Reilly Media: Publisher.

[35] Moggridge, B. (2007). Design interactions. Cambridge, MA: The MIT Press.

[36] Yang, Y. T. C., \& Wu, W.C. I. (2012). Digital storytelling for enhancing student academic achievement, critical thinking, and learning motivation: A year-long experimental study. Computers \& Education, 59(2), 339-352.

[37] Psomos, P., \& Kordaki, M. (2012). Pedagogical analysis of educational digital storytelling environments of the last five years. Procedia - Social and Behavioral Sciences, 69(24), 385-393.

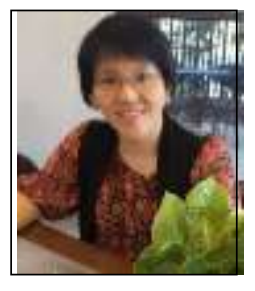

Pei-Fen $\mathbf{W u}$ is an associate professor at the department of Information Management \& Master program in Digital Content Technology and Management, National Chunghua University of Education, Taiwan. She received her MFA degree in Multimedia and Animation Arts from National Taiwan University of arts in 2002, and a PhD in design from National Yunlin University of Science and Technology in 2010. For the past, she worked more than 14 years in multimedia design industry. She started teaching at school from 2009. Teacher Wu led the students to participate in the contest that number of awards exceeded 60 . She also has won 8 outstanding teaching awards. She had published over 70 including journal and conference that use technology design to increase user' cognitive and affective. Her research interests include interactive media design, user-centered design, user experience, user interface, design thinking, digital story, user' cognitive, animation, technology-enhanced learning, and innovative design for the elderly.

Associate Prof. Pei-Fen Wu. Department of Information Management \& Master program in Digital Content Technology and Management, National Chunghua University of Education. 2, Shi-Da Road, Changhua City, Taiwan. (R.O.C.). 


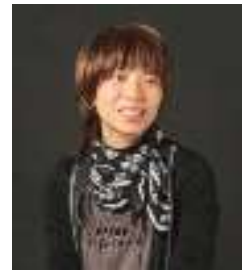

Hui-Jiun Hu is a Ph.D. in design from National Yunlin University of Science and Technology in Taiwan and is an associate professor in the Department of Visual Arts at National Chiayi University. Her research interests include visual communication design, user experience, UCD design, interactive design, and technology art. In recent years, she is devoted to the innovative design of smart living for the elderly and the community.

Associate Prof. Hui-Jiun Hu is with the Department of Visual Arts, National Chiayi University. 85, Wenlong, Minhsiung, Chiayi County 621, Taiwan (R.O.C.).

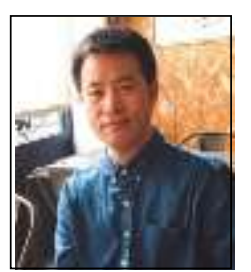

Kuang-Yi Fan is an assistant professor at the Graduate Institute of Animation and Multimedia Design, National University of Tainan, Taiwan. He received his MFA in Multimedia and Animation Arts from National Taiwan University of Arts in 2002, and a PhD in design from National Yunlin University of Science and Technology in 2013. His research interests include animation, design thinking, storytelling, and motion graphics design.

Assistant Prof. Kuang-Yi Fan. The Graduate Institute of Animation and Multimedia Design, National University of Tainan. 33, Sec. 2, Shu-Lin St., Tainan 700, Taiwan. (R.O.C.). 